Johannes Ungelenk

\title{
Rainer Maria Rilkes »Die Flamingos» Ein Kling(-ge-)ding
}

\author{
Die Flamingos \\ Fardin des Plantes, Paris
}

In Spiegelbildern wie von Fragonard ist doch von ihrem Weiß und ihrer Röte nicht mehr gegeben, als dir einer böte, wenn er von seiner Freundin sagt: sie war

noch sanft von Schlaf. Denn steigen sie ins Grüne und stehn, auf rosa Stielen leicht gedreht, beisammen, blühend, wie in einem Beet, verführen sie verführender als Phryne

sich selber; bis sie ihres Auges Bleiche hinhalsend bergen in der eignen Weiche, in welcher Schwarz und Fruchtrot sich versteckt.

Auf einmal kreischt ein Neid durch die Volière; sie aber haben sich erstaunt gestreckt und schreiten einzeln ins Imaginäre.

\section{I}

Kurt Oppert hat, vor allem gestützt auf Rilkes »Neue Gedichte", die Verbreitung der Bezeichnung 'Dinggedicht initiiert. $^{1}$ Obwohl die Forschung längst die Inadäquatheit der meisten Charakteristika, die Oppert unter anderem aus Rilkes Dinggedichten zu destillieren versuchte, her-

1 Vgl. Kurt Oppert, Das Dinggedicht. Eine Kunstform bei Mörike, Meyer und Rilke, in DVjs 4. 1926, S. 747-783. 
ausgearbeitet hat, ${ }^{2}$ ist die Bezeichnung noch immer weit verbreitet. Aus guten Gründen, wie die folgende Analyse von »Die Flamingos« vor dem Hintergrund von Rilkes nuancierten kunsttheoretischen Reflexionen des Dingbegriffs zeigen wird. Allerdings haften der vielfach rejustierten Typusbezeichnung >Dinggedicht` noch immer hartnäckig und nicht immer offensichtlich Reste einer intuitiven Konstellation von 'Ding` und lyrischem Sprechen an, die einst das Zentrum von Opperts Überlegungen gebildet hatte. ${ }^{3}$ Es ist daher das Projekt dieses Beitrags, Rilkes Arbeit an einem neuen, andersartigen Verhältnis von `Gedicht` und `Ding` freizulegen.

Oppert versteht das `Dinggedicht‘ als einen »Gegentypus« zu Goethes "werdende[m] Gedicht mit seiner subjektiven, echt lyrischen Stimmungshandlung «, »der auf unpersönliche, episch-objektive Beschreibung eines Seienden angelegt ist «. ${ }^{4}$ Demnach basiere das Dinggedicht auf einer Gegenüberstellung, die als Weltzugang der wissenschaftlichen Moderne allzu bekannt ist: >ein Seiendes` stehe dem sprechenden Subjekt als ’Ding، gegenüber, dessen Wahrheit es, ohne verfälschendes Zutun, sobjektive zu erfassen gelte. Für Oppert ist es freilich weniger die Wissenschaft als die Rilke zu seiner Pariser Zeit entscheidend prägende bildende Kunst,

2 Die sicher theoretisch avancierteste Darstellung des (Rilkeschen) Dinggedichts liefert Uwe C. Steiner in seinem Artikel Inständigkeit und Agency. Zur Problemgeschichte des Dinggedichts von der Emblematik bis Rilke und darüberhinaus. In: Ralf Simon, Nina Herres und Csongor Lörincz (Hg.) Das Lyrische Bild. München 2010, S. 299-318. Steiners Befund der Rilkeschen Inständigkeit des Dinges, die diesem selbst »agency« verschafft, bestätigt sich auch in der Lektüre der »Flamingos«. Stärker als das von Steiner analysierte Rilke-Gedicht "Der Ball« erzwingen "Die Flamingos" aber, Rilkes Verschiebung von Fragen der Mimesis und Repräsentation hin zur Erkundung des Dingcharakters des Kunstdings konsequenter mitzugehen. Gerade im Hinblick auf die Materialität des lyrischen Kunstdings helfen bildund d.h. repräsentationstheoretische Paradigmen, die auch bei Steiner noch eine gewisse Rolle spielen, nur bedingt weiter. Der Versuch ein 'Klingding< zu denken, versteht sich als eine Fortführung dessen, was Steiner theoretisch entwickelt, mit einer Akzentverschiebung auf die lautliche Materialität des Kunstdings hin.

3 Beispielhaft hierfür sind Wolfgang G. Müllers Ausführungen zum Dinggedicht im Rilke-Handbuch, Neue Gedichte/Der Neuen Gedichte anderer Teil. In: Manfred Engel (Hg.) Rilke-Handbuch. Leben - Werk - Wirkung. Stuttgart 2004, S. 296-317. Die "phänomenologische Dingkonzeption« (S. 298), die Müller Rilkes "Neuen Gedichten« zuschreibt, übernimmt Opperts problematische Grundkonstellation von einem Gegenstand, der vom beobachtenden Subjekt erfahren wird; das Problem des Primats des Subjekts in einer solchen Konstellation verschärft sich noch, wenn es, wie Müller schreibt, nicht das Ding als solches, sondern die Wahrnehmung von Dingen ist, die im Dinggedicht repräsentiert würden. Für eine Kritik dieses »kruden Subjekt-Objekt-Gegensatz[es]« s. Steiner Inständigkeit und Agency (wie Anm. 2), S. 312-313.

4 Oppert, Das Dinggedicht (wie Anm. 1), S. 747f.

\section{Johannes Ungelenk}


die dieses Subjekt/Objekt-(lyrisches Sprechen/Ding-)Verhältnis verbürge. "Das Dinggedicht wahrt enge Verwandtschaft zur bildenden Kunst «, ${ }^{5}$ schreibt Oppert, und identifiziert in Dinggedichten typisch »bildnerische Stoffer. ${ }^{6}$ Tatsächlich scheint seine oben zitierte Definition maßgeblich auf die beiden wohl bekanntesten Dikta Rilkes (bzw. seiner fiktionalen Figuren) zurückzugehen, die als Früchte seiner Beschäftigung mit Rodin und Cézanne gelten: auf Maltes "Ich lerne sehen « ${ }^{7}$ und auf die vielzitierte "Entwicklung zum sachlichen Sagen ${ }^{8}{ }^{8}$ die Rilke in einem der als "Briefe über Cézanne« später veröffentlichten Briefe an seine Frau konstatiert. Für Oppert vollzieht sich also in Dinggedichten (wie in aller Kunst!) eine »Wesensschau«: Das Subjekt nehme sich, wie ein bildender Künstler, ein 'Ding vor, um dessen Essenz zu erkennen (eine Frage des Sehens) und diese dann im Gedicht sachlich, »episch-objektiv[]« auszusagen.

Dem scheint die Grundkonstellation des »Die Flamingos« überschriebenen Sonetts auf den ersten Blick voll und ganz zu entsprechen. Exponiert doch der Titel genau jenes ein wenig rätselhafte und faszinierende >Ding - die Flamingos - dem sich dann das Gedicht widmet. Tatsächlich 'malt das Sonett eine einfache, von einem vornehmlich auf das Visuelle fokussierenden Beobachter wahrgenommene Szenerie. Karl-Heinz Fingerhut fasst diese in folgenden Worten zusammen:

Flamingos stehen im Wasser und spiegeln sich in ihm. Dann steigen sie ans Land und stehen dort zusammen, den Kopf unter die Fittiche gelegt. Ein Schrei erschreckt sie. ${ }^{9}$

Diese ssachlich gesagte Beschreibung der Beobachtungen des Gedichts wirkt im Vergleich zur konkreten lyrischen ’Realisierung« selbst äußerst schal. ${ }^{10}$ Folgerichtig erweist sich für frühe, von Opperts Typusbezeich-

5 Ebd., S. 754.

6 Ebd., S. 752.

7 Rainer Maria Rilke, Werke. Kommentierte Ausgabe in vier Bänden. Hg. von Manfred Engel u.a. Frankfurt a.M., Bd. 3 (1996): Die Aufzeichnungen des Malte Laurids Brigge, S. 453-635, hier S. 456.

8 Ebd., Bd. 4 (1996): Briefe über Cézanne, S. 594-636, hier S. 624.

9 Karl-Heinz Fingerhut, Das Kreatürliche im Werke Rainer Maria Rilkes. Untersuchungen zur Figur des Tieres. Bonn 1970, S. 160.

10 Dass es sich bei Fingerhuts robjektiver Paraphrase eher um eine durchaus fragwürdige Interpolation handelt, zeigt sich an Judith Ryans Zusammenfassung der vom Gedicht geschilderten Situation, die sich erheblich unterscheidet. Vgl. Judith Ryan, Umschlag und Verwandlung. Poetische Struktur und Dichtungstheorie in R. M. Rilkes Lyrik der mittleren Periode (1907-1914). München 1972, S. 42. 
nung noch stark geprägte Leser das Sonett als ein wenig gelungenes 'Dinggedichtr. So empfindet Johannes Pfeiffer die Vergleiche als "geziert und ausgekostet $[\ldots]$ bis zur Gestelztheit «: ${ }^{11}$ Man muss fragen,

ob diese Geschraubtheit nicht damit zusammen hängt, daß der auf Teilhabe am Eigenwesen der Erscheinungen gerichtete Ausdruckswille immer wieder abgleitet ins eben doch nur intellektuell Herangetragene: eine überzüchtete Subjektivität durchkreuzt mit ihren selbstbezüglichen Projektionen und Assoziationen die Hinwendung zur Wirklichkeit der Dinge. ${ }^{12}$

Unverkennbar beruht die Wertung des Gedichts auf der unterstellten Norm eines vorausgesetzten "Ausdruckwille[ns]«: In der Folge Opperts und offenbar inspiriert von phänomenologischem Denken setzt Pfeiffer die »Teilhabe am Eigenwesen der Erscheinungen« und die "Hinwendung zur Wirklichkeit der Dinge« als das hier verfehlte Ideal des Rilkeschen Dinggedichts. Angesichts des vernichtenden Urteils liegt der Verdacht nahe, dass das als Maßstab dienende Ideal dem betrachteten Dichten nicht gerecht wird. Im Falle der "Flamingos" wiegt dies umso schwerer, da das Sonett, wie im Folgenden gezeigt werden soll, gerade über und zugleich als das spricht, was Oppert und Pfeiffer vorschnell und zu trivial voraussetzen: über das Verhältnis von lyrischem Sprechen und `Ding« - über das Dinggedicht.

Rilkes "Die Flamingos" nimmt seinen Anfang nicht, wie erwartet werden könnte und wie der Titel auch gewissermaßen suggerieren mag, in der Beschreibung einer Beobachtung - sondern in einer vergleichenden ästhetischen Reflexion. Der auffallend unauffällige, zurückgezogene Sprecher bringt zwei mediale Alternativen des sbeschreibenden/darstellenden Bezugs zur Welt ins Spiel: 1. "Spiegelbilder[] wie von Fragonard" (V. 1) $)^{13}$ und 2. die Aussage eines Mannes, der »von seiner Freundin sagt: sie war / noch sanft von Schlaf.«(V. 3-5) Beide sind auf eine noch näher zu bestimmende Weise defizitär. Fragonards Rokokomalerei und die lyrisch angehauchte Proposition bleiben offensichtlich etwas schuldig. Die Formulierung, dass dem impliziten Leser (angesprochen im »dir«) durch das eine "nicht mehr gegeben" (V. 3) sei als durch das andere, suggeriert ein zu füllendes Desiderat, eine bessere Alternative des sdarstellenden

11 Johannes Pfeiffer, Über zwei Gedichte von Rilke. In: Ders., Über das Dichterische und den Dichter, Berlin 1967, S. 155-160, hier: S. 157.

12 Ebd.

13 Rilke, Werke (wie Anm. 7), Bd. 1 (1996): Der neuen Gedichte anderer Teil, S. 511-586, hier S. 575.

166 Johannes Ungelenk 
Weltbezugs. Erste Hinweise, worin denn das Schuldigbleiben begründet liege, ist den beiden medialen Alternativen jeweils subtil eingeschrieben: Fragonards Malerei ist mit "Spiegelbildern« identifiziert und dadurch als Kunstform qualifiziert, die sbloß abbildet, die sich damit begnügt, mimetisch zu repräsentieren. Die Aussage »sie war / noch sanft von Schlaf» problematisiert untergründig ihre Aussageposition und -struktur: Der über seine Freundin urteilende Mann stellt einen Weltbezug aus, dessen Hierarchisierung geschlechtlich klar kodiert und so auch leicht $\mathrm{zu}$ entlarven ist. Natürlich ist das sprechende Subjekt männlich und das sbetrachteter Objekt weiblich. Das gefällte Urteil reproduziert dann bloß das schon von der Ausgangskonstellation des männlichen Blicks auf und Sprechens über das weibliche, passive Objekt verkörperte Klischee.

Nun werden am Anfang von Rilkes Sonett aber nicht bloß Fragonards bildende Kunst und die die Geschlechterverhältnisse entlarvende Aussage als zwei in gleichem Maße defizitäre Alternativen ausgestellt; sie sind vielmehr miteinander identifiziert und beleuchten sich so gegenseitig. Der mediale Abstand zwischen der nur über den Künstlernamen aufgerufenen Rokokomalerei und der damit scheinbar gänzlich unverbundenen Aussage über die Freundin verdeckt, dass explizit die Eigenart der "Spiegelbilder[] « von Fragonard durch den Vergleich mit dem patriarchalen `Urteik näher bestimmt wird. Wieder ist es die starke Suggestionskraft des Titels und die vorschnelle Festlegung auf die Art des 'Dings`, um die es dem Sonett geht, die das Verständnis verstellen. Zwischen dem Gedichttitel und der Referenz des Sprechens am Gedichtbeginn besteht eine wichtige, aber viel zu selten beachtete Spannung. Der Leserin bleibt keine andere Wahl, als die Possessivpronomen des zweiten Verses, "von ihrem Weiß und ihrer Röte«, aufgrund der Absenz eines Referenten im vorausgehenden Gedichttext selbst zunächst auf den Gegenstand des Titels, also auf »Die Flamingos" zu beziehen. Doch liefert der Vergleich mit der Aussage des Mannes einen möglichen, alternativen Bezug nach: "seine Freundin", also eine weibliche Person. Die Ambivalenz des Possessivpronomens »ihrem", das sowohl als Singular weiblich als auch als Plural verstanden werden kann, ermöglicht erst den rätselhaften Auftakt des Gedichts. Denn Fragonard malt keine Flamingos, und es ist auch nicht seine "nuancierte Koloristik « ${ }^{14}$, die ihn als Vorbild für das Erfassen

14 Fingerhut, Das Kreatürliche im Werke Rilkes (wie Anm. 9), S. 160.

Rainer Maria Rilkes »Die Flamingos« 167 
der Farbspiegelungen im Wasser besonders geeignet machte - hierfür wären wohl die von Rilke geschätzten Impressionisten einschlägig. Das Weiß und die Röte, mit denen Fragonard sich beschäftigt, sind das Weiß und die Röte der nackten Frauenhaut:

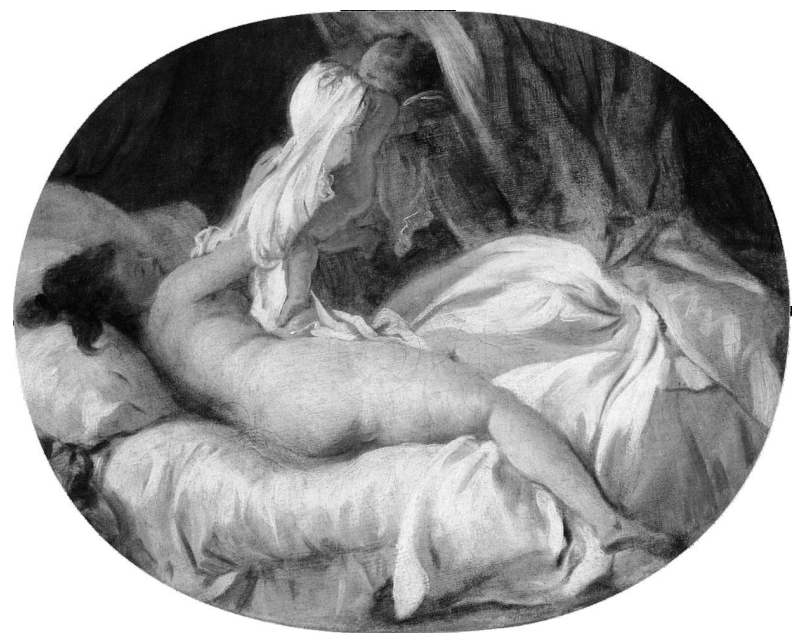

Abb. 1: Jean-Honoré Fragonard, La Chemise enlevée (ca. 1770)

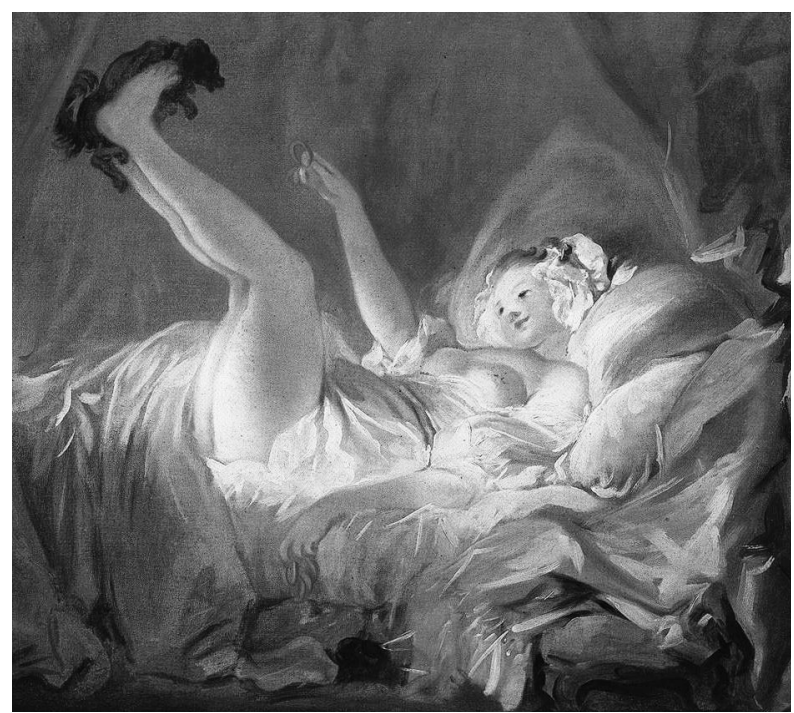

Abb. 2: Jean-Honoré Fragonard, Jeune fille faisant jouer son chien dans son lit (ca. 1770)

168 Johannes Ungelenk 
Wie die beiden zur beispielhaften Illustration recht wahllos aus einer größeren Gruppe ähnlicher Gemälde ausgewählten Bilder verdeutlichen, stehen Fragonards "Spiegelbilder« tatsächlich dem nahe, was sich vollzieht, wenn einer "von seiner Freundin sagt: sie war / noch sanft von Schlaf.« Schauplatz der repräsentierten Szenen ist die Bettstatt, auf der ein mit aller Art faltenwerfender Textilien aufwändig in Szene gesetzter Frauenkörper einer Beschäftigung gewidmet ist, die die Aufmerksamkeit der Frau bindet und so den Standpunkt des Malers und des Betrachters gewissermaßen unsichtbar macht. Es ist die Position eines Voyeurs, der, durch das Schlüsselloch linsend, einer an sich sunschuldigen< Situation 'heimlich und hinterrücks ihre erotischen Reize abgewinnt. Die Gemälde sind vom vielleicht männlichsten aller Blicke und Inszenierungskonstellation komponiert - ein männliches Künstlersubjekt beutet die oberflächlichen Reize (es geht tatsächlich vor allem um die Textur von Haut und Stoff) eines weiblichen Anschauungsobjekts aus: Es handelt sich um eine Form von ('sanfters) Pornografie.

Der Auftakt von Rilkes Sonett exponiert und kritisiert also einen spezifischen 'Dingbegriff^ und damit zugleich eine (ästhetische) ' $\mathrm{Zu}$ griffsweiser: Es ist der Begriff eines Dinges, das als ein passives (weibliches), von einem aktiven (männlichen) Subjekt betrachtetes und dann repräsentiertes Objekt definiert und konstituiert wird. Der Begriff des "Spiegelbilde[s]« spielt also auf das scheinbar srein` mimetische, 'getreu< abbildende Verfahren an, das Kurt Oppert als »unpersönliche, epischobjektive Beschreibung eines Seienden « ${ }^{15}$ vorschwebt. Mit dem Verweis auf Fragonard deckt Rilke aber die problematische Konstellation auf, die eine solche Struktur von repräsentierendem Subjekt versus repräsentiertem Objektding trägt. Was in Pfeiffers Worten so unschuldig »Teilhabe am Eigenwesen der Erscheinungen ${ }^{16}$ heißt, erweist sich als bloße geschlechtlich kodierte Struktur der aneignenden Ausbeutung. Das Problem ist also weniger, dass das Subjekt sich aufgrund seiner »überzüchtete[n] Subjektivität« und »selbstbezüglichen Projektionen und Assoziationen ${ }^{17}$ das vorgestellte Objekt verstellt, sondern dass es sich das Objekt bloß für seine Zwecke und zu seiner eigenen Stärkung entwirft und dienstbar macht.

15 Oppert, Das Dinggedicht (wie Anm. 1), S. 747f.

16 Pfeiffer, Über zwei Gedichte von Rilke (wie Anm. 11), S. 157.

17 Ebd. 
Dass das Gedicht in einer anderen Relation steht zum 'Ding`, um das es ihm geht, als einer episch-objektiv repräsentierenden, wird schon aus der bereits angesprochenen Spannung der Referenz ersichtlich. Explizit und eindeutig als rechtes` grammatisches Subjekt der Beschreibung haben die Flamingos ihren Auftritt erst im zweiten Quartett des Sonetts. In dem Personalpronomen »sie«, das sie grammatisch nun eindeutig, aber nach den Reflexionen des Eingangs völlig unvermittelt einführt, hallt das identische Personalpronomen aus dem vorangegangen Vers wider, das dort aber im Singular auf die weibliche Person der Freundin bezogen war. Spätestens durch diesen deutlich exponierten, abrupten Wechsel der Referenz ist klar markiert, dass das Sonett nicht schlicht ein im Pariser Jardin des Plantes anzutreffendes tierisches Beobachtungsobjekt beschreibt. Einer solchen Erwartung steht das kleine Wörtchen "Denn" entgegen, das den im zweiten Quartett beginnenden Satz einleitet. Obgleich hier nun einzusetzen scheint, was der Titel suggeriert hatte - nämlich eine lyrische Repräsentation der rosafarbenen Tiere -, bindet die einen Kausalzusammenhang herstellende Konjunktion die Beobachtung der Flamingos in die voranstehenden ästhetisch-medialen Überlegungen ein. Die folgende Beschreibung der Tiere liefert das Argument, warum sie nicht wie in "Spiegelbildern [...] von Fragonard", warum sie nicht wie im Urteil des die Freundin betrachtenden Mannes bloß repräsentiert werden können.

Dieses Argument durchläuft zunächst die erwartete lyrische Beschreibung, das kolportierte sgelernte Sehen`, das ssachliche Sagen der Flamingos. Wie der oben bereits erwähnte Brief Rilkes verrät, bildet der Vergleich der wie Blumen im Beet zusammenstehenden Flamingos die älteste Schicht des Sonetts, seinen Entstehungskern, aus dem heraus und um den herum das Gedicht entwickelt wurde. ${ }^{18}$ Das beobachtete Bild fungiert aber nur als Auftakt und Hintergrund für das entscheidende Charakteristikum, auf das das zweite Quartett hinzielt: die Flamingos "verführen", und zwar "verführender als Phryne» (V. 8). Wie Judith Ryan dargelegt hat ${ }^{19}$ speist Rilke mit der Erwähnung des Namens einer

18 Vgl. "es war fast schmerzlich, in dieser Luft ["Wind, der aus Schnee kam«] die rosa und roten Flamingos blühen zu sehen« (Rainer Maria Rilke, Briefe. Aus den Jahren 1902-1906. Hg. von Ruth Sieber-Rilke und Carl Sieber. Leipzig 1929, S. 300).

19 Vgl. Judith Ryan, More Seductive Than Phryne. Baudelaire, Gérôme, Rilke, and the Problem of Autonomous Art. In: PMLA 108, 1993, S. 1128-1141. 
griechischen Hetäre (dem ungefähren antiken Pendant einer Kurtisane oder 'Edelprostituiertens) einen schon in der Antike kursierenden, mehrfach besetzten medientheoretischen 'Topos` ein, der den Diskurs der bildenden Künste des ausgehenden 19. Jahrhunderts stark geprägt hat. Zum einen gilt Phryne als das Modell, nach dem Praxiteles das berühmte Standbild der "Aphrodite von Knidos" geschaffen hat. Um die Verführungskraft des steinernen Abbildes (das als eine der ersten Großplastiken einer nackten Frau gilt) rankt sich schon in der Antike eine rege Legendenbildung. Zum anderen fand eine Erzählung rasche und anhaltende Verbreitung, wonach in einem Prozess, der Phryne gemacht wurde und in dem der prominente Politiker Hypereides ihre Verteidigung übernommen hatte, Phryne einer Verurteilung durch Entblößung vor den Richtern entkommen sein soll. Judith Ryan kann zeigen, wie Jean-Léon Gérômes Gemälde "Phryné devant l'Aréopage« aus dem Jahr 1867, das diese Legende ins Bild setzt, eine kontroverse Diskussion im Diskurs der (vor allem akademischen!) bildenden Kunst des 19. Jahrhunderts zugleich auslöst und abbildet:

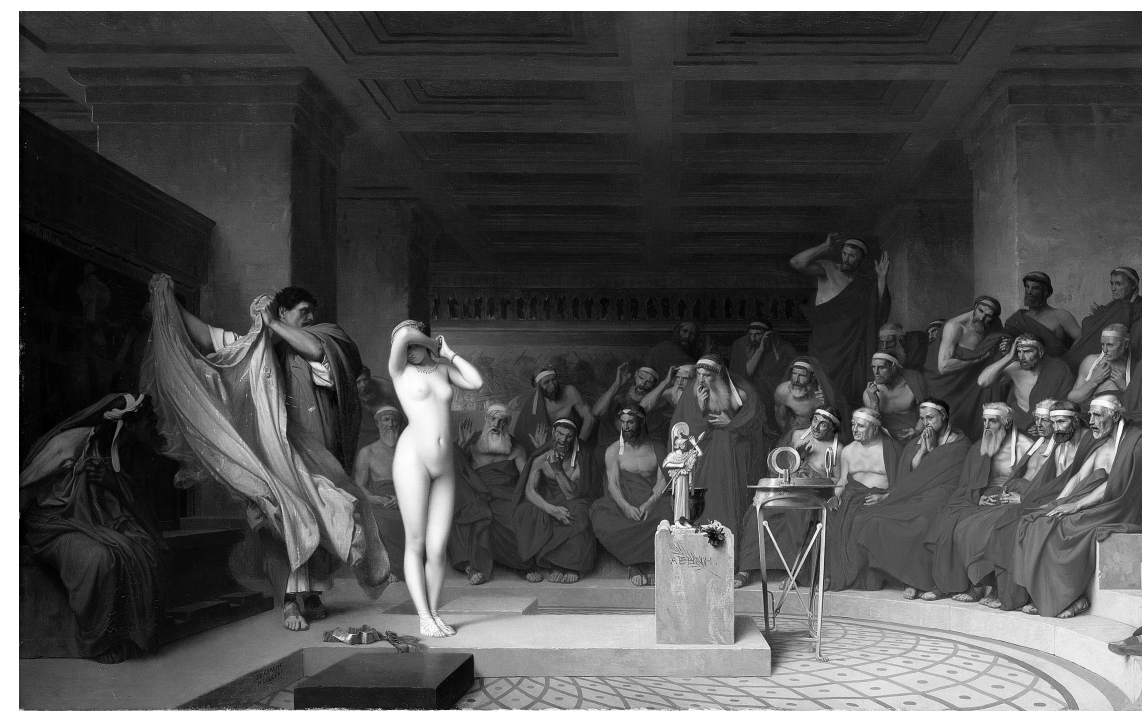

Abb. 3: Jean-Léon Gérôme, Phryné devant l'Aréopage (1861) 
Rilke aktualisiert diesen kulturellen Hintergrund nicht bloß durch die Erwähnung des Namens der Hetäre; bei genauerem Hinsehen zeigt sich, dass das gesamte zweite Quartett eine auf Phryne und das Verhältnis zu ihren Betrachtern fokussierende Fährte legt. Was Rilke um das >Urbild der blühenden Flamingos gruppiert, ist keineswegs bloß »episch-objektive Beschreibung « dessen, was er einst gesehen hatte. Wenn die Flamingos im sechsten Vers »stehn, auf rosa Stielen leicht gedreht«, beschreiben sie, untergründig, die durch zahlreiche antike Kopien und auch das Gepräge einer Münze wohlüberlieferte Pose der Aphrodite von Knidos. Das im ersten Quartett etablierte Oszillieren der Referenz von »ihrem Weiß und ihrer Röte« findet im zweiten Quartett seine konsequente Fortsetzung: Obwohl grammatisch auf die beobachteten Vögel und ihre Federfarbe bezogen, ist das dominante Thema doch ein erotisches, evozieren die angeführten Vergleiche doch allesamt das Beschauen und Abbilden/Repräsentieren von nackter Haut.

Jean-Léon Gérômes Gemälde illustriert anschaulich die Konstellation von weiblich-passivem `Ding und männlichem Künstler- und Beschauerblick. Es ist wenig verwunderlich, dass auch Gérôme sich mit dem Vorwurf konfrontiert fand, Pornografie zu betreiben. Zumindest reflektiert sein Bild aber, im Gegensatz zu Fragonards bloß das Fleisch abbildenden Spiegelbildern, die Konstellation, an der das Gemälde unstrittig noch selbst partizipiert. Gérôme wählt für sein Gemälde die Variante der Legende, nach der es Hypereides, der Verteidiger Phrynes, ist, der seine Mandantin, offenbar an das Ende seiner Rhetorik gekommen, vor den zu Gericht Sitzenden plötzlich entblößt. Die Geste gewinnt auf diese Weise ihre kunsttheoretisch so interessante, allegorische Dimension: Der Anwalt wird zur Ikone des Künstlers, der enthusiastisch sein Kunstwerk enthüllt - Phryne als Statue, man beachte die beiden Sockel, schwarz und weiß neben ihr - auf das gebannt alle, ausnahmslos männlichen Blicke gerichtet sind. Gérôme malt sich also selbst in sein Kunstwerk ein, und inszeniert sich als zeigender, enthüllender. Die Ausrichtung der Phryne signalisiert klar, dass der eigentliche Adressat dieses Zeigens der Betrachter des Bildes ist - zu ihm sind ihre Reize gewendet. Die teils empörte Menge der männlichen Kritiker spiegelt die Betrachterschaft in das Bild zurück - natürlich richtet sich das Kunstwerk nicht an den Einzelnen; doch gerade in der Multiplikation ist der betrachtende Blick als 
männlich markiert. Einzig Phryne blickt nicht - sie verbirgt die Augen in ihrem Arm. Das sollte nicht, wie Judith Ryan andeutet, ${ }^{20}$ vorschnell mit Rilkes Wendung der Legende identifiziert werden - das Verbergen des Gesichts ist keinesfalls eine Geste der Verführung, sondern der Scham. Im Grunde erfordern die klar geschlechtlich kodierten Blickverhältnisse die Abwesenheit ihres Blicks: Phryne schaut nicht, sie wird angeschaut. Sie ist das Ding, das als angesehenes, als Objekt des männlichen Blickes und Kunstwerks, nicht als selbst zurücksehendes, verführt.

Auch das 'Ding`, um das es Rilkes Sonett geht, scheint, so suggeriert es das zweite Quartett, wie Phryne von Gérômes Künstleranwalt, den Betrachtern rgezeigt<, in ihrem Wesen, ihrer Essenz, ihrer Schönheit offenbart zu werden. Und dies mit einem Effekt, der selbst die Verkörperung des Inbegriffs der antiken Schönheit noch übertrifft: „Die Flamingos" "verführen [...] verführender als Phryne« (V. 8). Doch wird diese Erwartung, dieser vorschnelle Schluss einer Aufgipfelung von einem überraschenden, das Ende der Oktave ins folgende Sextett des Sonetts überspielenden Enjambement jäh gebrochen. Mittels eines Hyperbatons spreizt Rilke den Satz geschickt so auf, dass der syntaktisch zur Vollständigkeit des Satzes nicht notwendige 'Zusatz "sich selber« als rejet im Terzett die Bedeutung des im zweiten Quartett Gesagten quasi retrospektiv, in letzter Sekunde wendet. "Die Flamingos" verführen nicht bloß besser als Phryne, sie verführen »verführender", weil sie anders verführen. Denn dieser Komparativ schließt an das bereits im ersten Quartett Entwickelte an; er setzt das dominante Thema des `Mehr-Gebens`, des >Überbietens‘ (vgl. V. 3) fort, wendet es aber vom Negativen ins Positive. Das, was "Die Flamingos« »verführender « macht als Phryne, scheint das entscheidende surplus zu sein, das Fragonards Spiegelbilder oder die Aussage des Mannes über seine Freundin nicht zu geben, zu bieten vermochten. In Rilkes Sonett wird es, und zwar als klar markiertes, als überraschendes surplus gegeben: zunächst als das Oktett überschießender Überschuss, als rätselhaftes "sich selber".

Wie die den Folgesatz einleitende Konjunktion »bis« anzeigt, spitzt das erste Terzett die offenbar charakteristische Selbstbezüglichkeit der Flamingos weiter zu. Schon die typische Situierung am Wasser und das Sprechen von "Spiegelbildern" evozieren in Verbindung mit der behaup-

20 Ebd., S. 1137.

Rainer Maria Rilkes »Die Flamingos« 173 
teten Selbstverführung den "Gedanke[n] an Narziß, an das Berauschtsein von der eigenen Schönheit« als "selbst-verständliche[n] Abschluß dieser Bildvorstellungen «. ${ }^{21}$ Die nun erzählte "gesture of narcissistic selfcontainment $«{ }^{22}$ das Bergen »ihres Auges Bleiche« »in der eignen Weiche« (V. 9-10), das die Flamingos vollziehen, treibt die Selbstbezüglichkeit noch einen Schritt weiter - und verschiebt sie dabei auf entscheidende Art und Weise. Bis zu diesem Zeitpunkt hatte die Vorstellung von Bildlichkeit, die Frage nach Repräsentation das Gedicht bestimmt; mit dem ersten Substantiv des Sonetts ("Spiegelbilder«) beginnend, über die ins Gedicht zitierte Präsenz der bildenden Kunst (»Fragonard«, Praxiteles' und Gérômes »Phryne«) bis hin zu dem vom lyrischen Sprechen selbst hergestellten Bild der blühenden Beete ist das Oktett vom dominanten Thema der visuellen, bildhaften Darstellung durchzogen. Die tatsächlich beobachtbare Geste des den Kopf ins Gefieder Steckens der Flamingos illustriert ikonisch die Abwendung von dieser Konstellation des Sehens und Abbildens. Anders als Narzissus verkümmern die Flamingos nicht als Resultat ihrer leeren und von der Welt des/r anderen ablenkenden Verfangenheit in der Selbstrepräsentation; im Gegenteil, statt Mangel resultiert ihr Selbstbezug in der Eröffnung unerhörter Fülle. "[I]hres Auges Bleiche« beschreibt nicht nur die äußere, blasse Erscheinung des Flamingokopfes; es relativiert vor allem, untergründig, die Kraft des bloßen Sehens - und damit die Subjekt-Objekt(//Ding)-Relation überhaupt. Denn die Bewegung, die sich nun vollzieht und die den absoluten Selbstbezug herstellt, ist genau das Gegenstück zur Vorgehensweise von Gérômes entblößendem, zeigendem Künstler-Anwalt: Die Flamingos bergen einen Teil ihrer selbst »in der eignen Weiche - und paradoxerweise erschließt sich erst so das "Schwarz und Fruchtrot« des inneren Gefieders der Flamingos, das eben "versteckt « ist und als solches nicht im Zeichen des Entblößens als das, was es ist, nämlich als Verstecktes, zugänglich ist.

Allerdings ist es keineswegs das »Schwarz und Fruchtrot« - im Übrigen perfekt visuell zugänglich -, welches über den dialektischen Kniff von Zeigen und Bergen als Essenz eines vorgestellten 'Dinges` nun "mehr gegeben" würde. Das Bergen der Flamingos in sich selbst, das Ab- und VerSchließen einer 'Figur in sich und als sie selbst bildet das Zentrum des

21 Fingerhut, Das Kreatürliche im Werke Rilkes (wie Anm. 9), S. 161.

22 Ryan, More Seductive Than Phryne (wie Anm. 19), S. 1138.

174 Johannes Ungelenk 
Gedichtes. Das aufwändig inszenierte "sich selber« beschreibt die Konstitution eines Dinges, das nicht mehr als ein passives, weibliches von einem männlichen Beobachterdarsteller zeigend-enthüllend in die Realität gestellt wird. Das Wesen dieses Dinges ist dem Modus der Schau und der damit verbundenen intellektuellen Aneignung nicht zugänglich; es widersteht der auf ein privilegiertes, erkennendes Subjekt ausgerichteten Grundkonstellation. Sein Wesen ist nicht sobjekthaft, sondern entfaltet sich aus nichts als dieser rätselhaften Wendung des "sich selber".

"Die Flamingos" sind nicht der Ort, an dem Rilke diesen Dingbegriff entwickelt und mitteilt. Sie explizieren und illustrieren vor allem das Ergebnis von Rilkes Beschäftigung mit Rodin und dessen Kunst der Plastik. Theoretisch dargelegt hat Rilke diesen für ihn folgenreichen Dingbegriff in seinem Rodinbuch. Die Formulierungen dort zum "Bildwerk" als »Ding, das für sich allein bestehen konnte « ${ }^{23}$, sind längst berühmt geworden. Ruft man sich einige dieser Worte Rilkes zurück ins Gedächtnis, gewinnen die so scheinbar lapidar eine Beobachtung beschreibenden Verse des Sonetts eine tiefere Bedeutung:

Was die Dinge auszeichnet, dieses Ganz-mit-sich-Beschäftigtsein, das war es, was einer Plastik ihre Ruhe gab; sie durfte nichts von außen verlangen oder erwarten, sich auf nichts beziehen, was draußen lag, nichts sehen, was nicht in ihr war. Ihre Umgebung mußte in ihr liegen. ${ }^{24}$

Deshalb, folgert Rilke, muss »der große Kreis [...] sich schließen, der Kreis der Einsamkeit, in der ein Kunst-Ding seine Tage verbringt « ${ }^{25}$. Es ist genau dieser Moment des Schließen des Kreises, den »Die Flamingos" erzählen: die Wendung der Verführung auf "sich selber", das Bergen der Augen in die "eigne[] Weiche«, die das visuell hierarchisierte Verhältnis von sehend-erkennendem Subjekt und beschautem Objekt->Ding« hinter sich lassen.

Was Neumann Rilkes "fundamentale Verwindung der klassischen Erkennungsszene ${ }^{26}$ durch »Überschreitung des Repräsentationscha-

23 Rilke, Werke (wie Anm. 7), Bd. 4 (1996): Auguste Rodin, S. 401-513, hier S. 410.

24 Ebd., S. 418.

25 Ebd. Auch in Rilkes Briefen über Cézanne hat dieses Paradigma des in sich und für sich geschlossenen Dinges offenbar noch alle Gültigkeit: »Seine Nature morte sind so wunderbar mit sich selbst beschäftigt.« Rilke, Briefe über Cézanne (wie Anm. 8), S. 634.

${ }^{26}$ Gerhard Neumann, Rilkes Dinggedicht. In: Dagmar Ottmann (Hg.), Poesie als Auftrag. Würzburg 2001, S. 142-162, hier S. 157. 
rakters von Kunst hin auf eine 'Dingwerdung « ${ }^{27}$ nennt, wird bei Rilke explizit als eine geschlechtliche Frage reflektiert. In seinem Rodinbuch konstatiert Rilke eine Entwicklung:

[...] aus einem Trieb [war] eine Sehnsucht geworden, aus einer Begierde zwischen Mann und Weib ein Begehren von Mensch zu Mensch. Und so erscheint sie im Werke Rodins. Noch ist es die ewige Schlacht der Geschlechter, aber das Weib ist nichtmehr das überwältigte oder das willige Tier. Sie ist sehnsüchtig und wach wie der Mann, und es ist, als hätten sie sich zusammengetan, um beide nach ihrer Seele zu suchen. ${ }^{28}$

Auch das Sonett "Die Flamingos" ist, wie die Kunst Rodins, dieser "andere[n] Historie « ${ }^{29}$ gewidmet. Wie oben bereits ausgeführt, steht das Oktett, mit Fragonard, dem Freund der über seine Freundin spricht und der Bildtradition um Phryne noch ganz im Zeichen der "Begierde zwischen Mann und Weib«. Erst mit der entscheidenden Wendung, auf die das Sonett hinzielt, geschieht auf dieser skassischen Kontrastfolie auch in Hinblick auf Geschlechtlichkeit ein Paradigmenwechsel, der das 'Ding، "Die Flamingos« von einem »überwältigte[n] "willigen Tier« zu etwas "sehnsüchtig[em] und wach[em]« macht, zu etwas, das eben nicht mehr bloß »sanft von Schlaf« (V. 5) ist. Ein erster Hinweis dafür ist, dass das offensichtlich narzisstische Grundgefüge mit "Spiegelbildern", der Dominanz von Visualität und der von dieser induzierten Selbstverführung trotz des männlichen grammatischen Geschlechts des Flamingos nicht über die naheliegende mythologische Figur des Narzissus reflektiert wird. Im Gegensatz zu Zeitgenossen, die den altbekannten Mythos affirmativ als Grundfigur der intellektuellen Reflexion neu (und zugleich in geschlechtlicher Hinsicht uralt!) besetzen, ${ }^{30}$ greift Rilke auf die kryptischere Figur der Phryne zurück. Phryne ist unheimlich, ja paradigmatisch weiblich, und kann, genau weil sie weiblich ist, zur Trägerin der »anderen Historie« werden, um die es Rilke geht. Wie wiederum Judith Ryan in ihrem erhellenden Aufsatz erschlossen hat, verbirgt sich im Assoziations- und Resonanzraum dieses legendenumrankten Namens selbst eine Art Kippfigur - eine Kippfigur derselben Art, wie die, die das Sonett, just als dieser Name fällt,

27 Ebd., S. 151.

28 Rilke, Auguste Rodin (wie Anm. 23), S. $425 f$.

29 Ebd., S. 425.

30 Vgl. z.B. in Hinblick auf Paul Valéry und Stéphane Mallarmé Ursula Franklin, Valéry's Broken Angel. In: Romanic Review 74, 1983, S. 355-373, hier S. 357f.

176 Johannes Ungelenk 
tatsächlich auch vollzieht: Phryne fungiert nicht nur, wie oben referiert, als das Paradigma des weiblichen »überwältigte[n]" und "willige[n] Tier[s]«, an dem sich die pornografische Grundstruktur des "Repräsentationscharakters der Kunst" besonders deutlich aufzeigen lässt. Sie ist zugleich mit einer fundamentalen geschlechtlichen Umbesetzung einer der Kunst zu Grunde liegenden Konstellation assoziiert, und zwar über einen intertextuellen Bezug zu Baudelaire. "In part, the poem is a response to 'Les fleurs du mal«, schreibt Judith Ryan, "specifically to 'Lesbos`, one of the six poems condemned in Baudelaire's obscenity trial of 1847.«1 Zitiert seien von insgesamt 15 die Strophen drei und vier, die besonders einschlägig für Rilkes Sonett sind und an denen sich der Bezug deutlich ausmachen lässt:

$[\ldots]$

Lesbos, où les Phrynés l'une l'autre s'attirent, Où jamais un soupir ne resta sans écho, A l'égal de Paphos les étoiles t'admirent, Et Vénus à bon droit peut jalouser Sapho!

Lesbos, où les Phrynés l'une l'autre s'attirent,

Lesbos, terre des nuits chaudes et langoureuses, Qui font qu'à leurs miroirs, stérile volupté !

Les filles aux yeux creux, de leurs corps amoureuses, Caressent les fruits mûrs de leur nubilité ;

Lesbos, terre des nuits chaudes et langoureuses, $[\ldots]^{32}$

Baudelaires lesbische Phrynen sind klar mit Ovids Narzissus identifiziert. Sie machen Liebe nur mit ihren Spiegelbildern, eine Form der Lust, die gerade im Angesicht der Reife ihrer Früchte, ihrer Heiratsfähigkeit, provokant ssterik bleibt. Dennoch beneidet selbst Venus diesen Liebesort und den Inbegriff seiner lesbischen Lebensart, Sappho. Und zwar mit gutem Recht: Im Gegensatz zu Narzissus beruht die Lust der Phrynen nicht auf männlicher Verblendung durch das eigene Ego; statt sich in Selbstbegeisterung der Welt und dem anderen zu verschließen und als Ego zu vereinzeln, stellt die Beschäftigung der Phrynen mit sich als Spiegelbildern

31 Ryan, More Seductive Than Phryne (wie Anm. 19), S. 1130.

32 Charles Baudelaire, Euvres complètes. Hg. von Claude Pichois und Jean Ziegler. 2 Bde. Paris 1975, Bd. 1: Les épaves, S. 148-178, hier: S. 150. 
einen Bezug des einen zum anderen her. Genau wie Rilkes "Die Flamingos« übersetzt Baudelaires "Lesbos" den Narzissusmythos nicht nur ins Feminine, sondern auch in den Plural. Es entsteht eine eigenartige Figur, die, wie die Insel Lesbos bei Baudelaire, in sich zwar geschlossen, also nur sfür sich ist und sich "auf nichts bezieh[t], was draußen lag“, aber dennoch in sich Beziehungen birgt, die alles andere als steril sind oder zu narzisstischer Verkümmerung führen. Nie bleibt ein Seufzer ohne Echo, dichtet Baudelaire und schreibt mit dieser Aussage den Mythos von Narzissus und Echo neu. Hatte doch Narzissus, in seiner Entzückung vor dem eigenen Spiegelbild, die Liebe der Nymphe Echo verschmäht, die genau wie er anschließend aus fehlender Erwiderung vergeht. Auf Lesbos, das bekanntlich nicht nur Stätte der Liebe, sondern auch des (sapphischen) Dichtens ist, findet das offenbar lustvolle, scheinbar narzisstische "Ganzmit-sich-Beschäftigtsein« der Phrynen unerhörterweise unter Einbindung Echos statt. Alles andere als dichterisch steril sind die heißen und sehnsuchtsvollen Nächte, trotz oder gerade wegen ihrer 'Widernatürlichkeit‘.

Auch Rilke besetzt eine solche auf den ersten Blick lasterhafte Konstellation schon im Rodinbuch positiv:

Und in allen Lastern, in allen Lüsten wider die Natur, in allen diesen verzweifelten und verlorenen Versuchen, dem Dasein einen unendlichen Sinn zu finden, ist etwas von jener Sehnsucht, die die großen Dichter macht. Hier hungert die Menschheit über sich hinaus. Hier strecken sich Hände aus nach der Ewigkeit. Hier öffnen sich Augen, schauen den Tod und fürchten ihn nicht $[\ldots]]^{33}$

Verschiedene Indizien - nicht nur das äußerlich-biografische, dass Rilke durch Rodin zu Baudelaire gefunden hat - legen nahe, dass Rilke schon hier das als anstößig verbotene Gedicht »Lesbos" vor Augen hatte. Gerade der insistierende Begriff der Sehnsucht scheint aus Baudelaires "nuits chaudes et langoureuses" gespeist zu sein. In der gerade zitierten Stelle aus dem Rodinbuch macht »jene[] Sehnsucht » »die großen Dichter« und charakterisiert, wenige Sätze zuvor (s.o.), die »andere Historie«: »[...] aus einem Trieb war eine Sehnsucht geworden «. ${ }^{34}$

33 Rilke, Auguste Rodin (wie Anm. 23), S. 426.

34 Ebd., S. 425.

178 Johannes Ungelenk 
Diese Sehnsucht markiert, dass die scheinbar sterile Wendung des Dinges auf sich selbst, das Schließen des "große[n] Kreis[es] [...] der Einsamkeit ${ }^{35}$ - als die "Dingwerdung - kein versiegelndes Abschließen ist, sondern im Gegenteil eine besondere Öffnung generiert: »Hier hungert die Menschheit über sich hinaus. Hier strecken sich Hände aus nach der Ewigkeit. Hier öffnen sich Augen, schauen den Tod und fürchten ihn nicht«.

Bis hierher habe ich Rainer Maria Rilkes "Die Flamingos" einer im Grunde allegorischen Lektüre unterzogen. Ich habe es als eine Art Metagedicht gelesen, das zentrale kunsttheoretische Fragen diskutiert, die auch für den Dichter Rilke poetologisch von großer Relevanz sind. Doch unterscheidet sich das Sonett, trotz der offenkundigen Nähe zu Rilkes Rodinbuch, fundamental von diesem: Es liefert nicht nur kritische Reflexionen zum historischen und zeitgenössischen Status des Kunstwerks es ist zugleich selbst eines. Es reformuliert nicht nur Rilkes These eines Verlangens der "menschlichen Seele« »nach dieser Kunst, die mehr giebt als Wort und Bild, mehr als Gleichnis und Schein: nach dieser Dingwerdung ihrer Sehnsüchte und Ängste « ${ }^{36}$; es tritt als Kunstwerk selbst die Herausforderung an, diesem Verlangen gerecht zu werden, es ins Werk zu setzen. Als Sonett - und eben nicht kunsttheoretischer oder poetologischer Essay - genügt es nicht, anhand der beobachteten Flamingos allegorisch die Dingwerdung nachzuzeichnen - das Sonett, als Kunstwerk, stünde vor der Aufgabe, diese "Dingwerdung« der »Sehnsüchte und Ängste« selbst zu vollziehen.

Wie oben bereits herausgearbeitet, exponiert das Oktett die Frage des Rodinbuches in Form eines Desiderats: eben mehr zu geben als Fragonards »Spiegelbilder", mehr zu bieten als die Worte des Gleichnisses von der noch schläfrig-sanften Freundin. Doch wie ist dieses Desiderat zu erfüllen, wie ist einzulösen, dass Kunst »mehr giebt als Wort und Bild, mehr als Gleichnis und Schein«? 
In der bildenden Kunst seiner Zeit hat Rilke inspirierende Antworten gefunden. Es ist die Hinwendung zum Material, die den Repräsentationscharakter von Wort, Bild, Gleichnis und Schein überwindet. Rodins Plastiken legen durch ihre Materialität »Konflikte« frei, die »im Unsichtbaren lagen. Ihre Sprache war der Körper.« ${ }^{37}$ An Cézannes Malerei lernt und bewundert Rilke, »daß es die Farbe ist, die die Malerei ausmacht. « ${ }^{38}$ Kunst hat, das leben die Vorbilder Rodin und Cézanne eindrucksvoll vor, unerwartet viel mit geduldig-hingebungsvoller, dem Material gewidmeter Arbeit und weniger mit ingeniöser Inspiration zu tun. Besonders eindrücklich zeigt sich das in Rilkes Ausführungen zu Rodins Kunst der Oberfläche:

Aus all den großen anspruchsvollen und launenhaften Worten scheint die Kunst aufeinmal ins Geringe und Nüchterne gestellt, ins Alltägliche, ins Handwerk. Denn was heißt das: eine Oberfläche machen?39

Kunst ist Handwerk, ist mühsame, Fleiß erfordernde Arbeit am Material. Und doch ist es genau diese versessene Arbeit, die Gestaltung der Oberfläche, die die Plastik als Ding, als Kunstwerk auszeichnet, das eben "mehr giebt«:

Neu ist die Art von Bewegung, zu der das Licht gezwungen wird durch die eigentümliche Beschaffenheit dieser Oberfläche, deren Gefälle so vielfach abgewandelt ist, daß es da langsam fließt und dort stürzt, bald seicht und bald tief erscheint, spiegelnd oder matt. Das Licht, das eines dieser Dinge berührt, ist nicht mehr irgend ein Licht, es hat keine zufällige Wendungen mehr; das Ding nimmt von ihm Besitz und gebraucht es wie sein eigenes. ${ }^{40}$

Ganz ähnlich verhält es sich mit Cézannes Malerei und der Materialität der Farben. Rilke betont,

wie sehr das Malen unter den Farben vor sich geht, wie man sie ganz allein lassen muß, damit sie sich gegenseitig auseinandersetzen. Ihr Verkehr untereinander: das ist die ganze Malerei. Wer dazwischenspricht, wer anordnet, wer seine menschliche Überlegung, seinen Witz, seine Anwaltschaft, seine

37 Ebd.

38 Rilke, Briefe über Cézanne (wie Anm. 8), S. 606.

39 Rilke, Auguste Rodin (wie Anm. 23), S. 458.

40 Ebd., S. 462.

180 Johannes Ungelenk 
geistige Gelenkigkeit irgend mit agieren läßt, der stört und trübt schon ihre Handlung. ${ }^{41}$

Es ist also wenig verwunderlich, dass Rilkes Sonett, anders als seine kunsttheoretische Kritik, das eigene `Geben` nicht intellektuell fassen und der Leserin leitend an die Hand geben kann. Aus der Abwesenheit dieser souveränen Erklärungen wie Karl-Heinz Fingerhut zu folgern, es sei "auch die Absicht des Dichters, snicht mehr zu geben « ${ }^{42}$, geht daher fehl. Im Gegenteil ist es genau diese Abwesenheit, die es der "Handlung«, dem Vollzug, dem Tun, der Performanz des Gedichtes überlässt, ungestört und ungetrübt sich als Kunstwerk zu geben.

Von Rilkes faszinierter Reflexion der bildenden Kunst auf die Spur gesetzt, bliebe also die Aufgabe, der >Materialität ‘ von Rilkes Dichten nachzuforschen. Doch gerade für Lyrik als intellektuell durchwirkte Sprachkunst, die von Metapher und analogischem Sprechen lebt, scheint dieser Anspruch, mehr zu geben "als Wort und Bild, mehr als Gleichnis und Schein«, schwer einlösbar. Fällt in ihr nicht Rodins innovative Eigenart, nämlich dass die Sprache seiner Plastiken Körper war, wieder in sich, in das alte Muster zurück, ist nicht der >Körper`, das Material des Gedichtes, schlicht Sprache?

Und doch gibt Rilke in "Die Flamingos" einen kleinen Wink, der auf das charakteristische Überschießen, auf die Materialität seines Gedichts hinweist. Das initiale Terzett bringt an seinem Ende zum ersten Mal einen syntaktischen Abschluss mit einer metrischen Einheit zur Deckung, so dass sich die Verse eins bis elf zu einer kompakten Einheit schließen. Das zweite Terzett trägt Züge einer konkludierenden Coda: Vers 12 bringt die bisher völlig abwesende Umgebung der Flamingos ins Spiel, exemplarisch an der benachbarten Volière. Es ist eine Störung, die die sich in sich selbst bergenden Flamingos ereilt: "Auf einmal kreischt ein Neid durch die Volière« (V. 12). Diese Störung wird von den Flamingos offenbar wahrgenommen, denn sie lösen ihre charakteristische Geste, »haben sich erstaunt gestreckt« (V. 13). So wird markiert, dass im zentralen, selbstbezüglichen Bergen des Kopfes sich eine Wendung der sinnlichen Aufmerksamkeit vollzieht: War vorher das (kritisierte) Visuelle dominant, tritt nun neben dem Haptischen (die »eigne[] Weiche«) vor

41 Rilke, Briefe über Cézanne (wie Anm. 8), $627 f$.

42 Fingerhut, Das Kreatürliche im Werke Rilkes (wie Anm. 9), S. 160. 
allem das Akustische auf den Plan. "Auf einmal« wird Auditives thematisch und löst damit, zumindest für einen Vers, die starke Orientierung am Bildhaften ab. Unüberhörbar fällt in diesem Vers das ThematischWerden des Akustischen mit der lautmalerischen Performanz des Gedichtes zusammen. Der Vers baut das onomatopoetische Potenzial des $\mathrm{Kreischens} \mathrm{durch} \mathrm{darum} \mathrm{gruppierte} \mathrm{Assonanzen} \mathrm{auf} \mathrm{den} \mathrm{Laut} \mathrm{[ei]} \mathrm{aus}$ (»Auf einmal kreischt ein Neid«). Für einen Moment fallen die Aufmerksamkeit der Flamingos - die offenbar mit sich selbst beschäftigt und in sich selbst geschlossen zwar nicht sehen, aber sehr wohl hören können und die Aufmerksamkeit der impliziten Leserinnen zusammen. Hatte sich bis zu diesem Moment auch in der Beschreibung des Gedichts der ralte`, dem "Repräsentationscharakter[] von Kunst « ${ }^{43}$ inhärente Abstand zwischen der äußerlichen Beobachtung eines Dinges und dessen Eigenleben scheinbar perpetuiert, macht doch hier plötzlich ein 'Kanak auf sich aufmerksam, der diesen an der visuell orientierten Subjekt-ObjektKonstellation festzumachenden Abstand überschreitet. Es ist wichtig, dass es sich nicht um irgendeine mutwillige Störung von außen handelt; der Verweis auf »Neid « ${ }^{44}$ unterstreicht, dass die Störung sich durchaus mit der Eigenheit »der Flamingos" identifiziert. Denn das einbrechende Akustische ist, wie wir sehen werden, dem Vorangegangenen keineswegs fremd; es übersteigert nur dessen Charakteristikum, äfft es gewissermaßen nach, und hebt es so an die thematische Oberfläche.

Das Sonett materialisiert, was Rilke der Rodinschen Plastik nur metaphorisch zuschreiben konnte: "Immer und immer wieder kam Rodin bei seinen Akten auf dieses Sich-nach-innen-Biegen zurück, auf dieses angestrengte Horchen in die eigene Tiefe ${ }^{45}$ Es ist komponiert aus dem Material Klang - und horcht, tatsächlich, dem klingenden Spiel angestrengt nach, das der Sprache der Welt innewohnt. Der "hinhalsend [...] in der eignen Weiche" geborgene Kopf der Flamingos inszeniert diese Haltung; er ist, genau wie die Gazelle aus Rilkes gleichnamigem Tierdinggedicht,

43 Neumann, Rilkes Dinggedicht (wie Anm. 26), S. 151.

44 Die Vokabel des Neids stellt zudem eine weitere interessante Verbindung zu Baudelaires oben zitiertem Gedicht her, wo es ja heißt: "Lesbos, où les Phrynés l'une l'autre s'attirent, / [...]. Et Vénus à bon droit peut jalouser Sapho!« (Vielen Dank an Inka Mülder-Bach für den Hinweis auf diese Beobachtung.)

45 Rilke, Auguste Rodin (wie Anm. 23), S. 420.

182 Johannes Ungelenk 
die »das Haupt ins Horchen hält « ${ }^{46}$, eine metapoetische Figur: der Nabel des Gedichtes, die Stelle, wo sich das Gedicht auf sich selbst bezieht und damit auf seine ihm eigene Materialität verweist. Deshalb assoziiert Rilke auch, wenn er seiner Frau über Cézannes Umgang mit Farbe berichtet, an einer der seltenen Stellen, an der er explizit den Bogen zu seiner eigenen, dichterischen Kunst herstellt, als Epitom des gerade in den Druck gehenden ersten Teils der "Neuen Gedichte« gerade dieses Gedicht: "In den Gedichten sind instinktive Ansätze zu ähnlicher Sachlichkeit. Die `Gazeller lasse ich auch stehen: sie ist gut. Leb wohl ...«47 "Die Flamingos« schreibt Rilke deutlich später; hier ist die Analogie, die »ähnliche Sachlichkeit«, nicht mehr instinktiv, sondern ausgearbeitet. Wieder wählt er die Form des Sonetts.

Gewissermaßen tritt er damit das Erbe Rodins an, von dem er erzählt, dass Dantes und Baudelaires "Sonette, die wie Säulen mit verworrenen Kapitälen die Last eines bangen Gedankens trugen ${ }^{48}{ }^{4}$ Rodin zu der 'Art Kunst geführt haben, die nun Rilke so fasziniert. Wie Judith Ryan anmerkt, äußert sich Rilke zur Tradition, in der er sich mit der Auswahl der Formen für die "Neuen Gedichte« einschreibt, merkwürdigerweise nicht - dabei sind die Anleihen vor allem bei Baudelaire (Sonette, Quatrains und längere Gedichte in Alexandrinern) recht offensichtlich. ${ }^{49}$ Ein Grund hierfür dürfte sein, dass die Wahl der Form essenziell mit Rilkes Poetologie, insbesondere mit seinem Dingbegriff zu tun hat, was eine Selbstverortung in der Tradition als Motivation eher verdecken würde. Dennoch bestehen natürlich wichtige Verbindungen. So bewundert Rilke an Baudelaires »Fleurs du Mal«, "wie diese Gedichte in ihrem Mitsich-Gesättigtsein keine Ergänzung zulassen und keine Steigerung über sich hinaus $\aleph^{50}$. Die Nähe zu Rilkes Äußerung über Cézannes natures mortes, die "so wunderbar mit sich selbst beschäftigt «" ${ }^{51}$ sind, ist unübersehbar. Diesem Ideal der dichten, gesättigten Geschlossenheit ist das Sonett auf besondere Art und Weise zugeneigt, wie Rilke meisterhaft mit "Die Flamingos« vorführt.

\footnotetext{
46 Rilke, Werke (wie Anm. 8), Bd. 4 (1996): Neue Gedichte, S. 447-510, hier S. 470 (V. 12).

47 Rilke, Briefe über Cézanne (wie Anm. 8), S. 617.

48 Rilke, Auguste Rodin (wie Anm. 23), S. 413.

49 Vgl. Ryan, Umschlag und Verwandlung (wie Anm. 10), S. 55.

50 Rilke, Auguste Rodin (wie Anm. 23), S. 431.

51 Rilke, Briefe über Cézanne (wie Anm. 8), S. 634.
} 
Es ist kein Zufall, dass sich Rilke erst mit den "Neuen Gedichten", unter Einfluss Rodins und im Hinblick auf seine Beschäftigung mit dem Dingbegriff, der Gedichtform Sonett bedient. ${ }^{52}$ Das Sonett gilt als strenge Form, deren enge metrische Forderungen ein hohes Maß an handwerklichem Umgang mit dem Lautmaterial abverlangen. Was vielen Dichterkollegen deshalb als beschneidende Einschränkung, als überflüssiger Zwang erscheint, macht für Rilke diese Form so reizvoll: Das Sonett ist über die definierende Forderung von vierzehn Versen von vorneherein eine geschlossene Form - lässt also ganz ikonisch »keine Ergänzung« zu. Es konstituiert so, in Analogie zu Rodins frühen Plastiken, ein kompaktes, für sich stehendes Kunstwerk, das durch und durch rgeformt und komponiert ist und daher »keine zufälligen Wendungen « ${ }^{53}$ mehr kennt. Das anspruchsvolle Reimschema, das die Gliederung des Gedichtes in zwei Quartette und zwei Terzette und damit auch Erwartungen an eine thematische Struktur erzeugt, ist Garant für das geforderte »Mit-sich-Gesättigtsein" des Kunstwerks. Zudem macht die reiche Tradition des Sonetts, die Weltliteratur von Dante, Petrarca, Ronsard, über Shakespeare und viele mehr in sich vereint, dass jedes Sonett sich "mit sich selbst beschäftigt«, indem es, als Sonett, gar nicht anders kann, als sich zu den Vorläufern zu verhalten. Wie aber dem Sonett bereits in seinem Namen eingeschrieben ist, handelt es sich bei diesem Selbstverhältnis vor allem um eines: um Beschäftigung mit dem Klang, aus dessen Komposition sich ein in sich geschlossenes, sich gewissermaßen aus dem eigenen Echo, aus dem »angestrengte[n] Horchen in die eigene Tiefe« konstituierendes Ding formt. ${ }^{54}$

Rilkes "Die Flamingos" kommen der als französischen Variante des Sonetts bekannten Ausprägung am nächsten: Die Quartette sind als umarmende Reime gestaltet, wobei, wie im Deutschen aufgrund der Armut

52 Vgl. Ryan, Umschlag und Verwandlung (wie Anm. 10), S. 59. Die enge Verbindung des Konzeptes 'Dinggedicht $`$ mit der Form Sonett unterstreicht auch das Faktum, dass es sich bei den exemplarischen rilkeschen Dinggedichten, die Gerhard Neumann in seinem dem Dinggedicht gewidmeten Aufsatz analysiert, ausgerechnet um zwei Sonette handelt, vgl. Neumann, Rilkes Dinggedicht (wie Anm. 26).

53 Rilke, Auguste Rodin (wie Anm. 23), S. 462.

54 In Hinblick auf den konstitutiven Dingcharakter des Gedichtes vgl. Roman Jakobson, Closing Statement: Linguistics and Poetics. In: Thomas A. Sebeok (Hg.), Style in Language. Cambridge 1960, S. 350-377, hier S. 371: "This capacity for reiteration whether immediate or delayed, this reification of a poetic message and its constituents, this conversion of a message into an enduring thing, indeed all this represents an inherent and effective property of poetry." 
an gleichen Reimen üblich, das zweite Quartett sich neuer Reimpaare bedient. Die Kadenzen alternieren zwischen stumpf und klingend. Das Reimschema der Terzette (eeF gFg) ist von Ronsard her bekannt und setzt den Wechsel der Kadenzen konsequent fort.

Wie bei Rilke gewohnt, treten syntaktische und metrische Struktur mitunter kräftig in Spannung. Das Gedicht setzt direkt mit zwei Enjambements ein, und insbesondere die jeweils die Enden der Quartette überspielenden starken Enjambements ziehen Aufmerksamkeit auf sich. Johannes Pfeiffer spricht deshalb sogar von einer "wesenswidrigen Erweichung einer vorgegebenen Struktur«, »die nun einmal ihr objektives Sinngesetz und damit ganz bestimmte Forderungen in bezug auf das Verhältnis von Spannung und Lösung in sich trägt. ${ }^{55}$ Doch generiert, bei genauerem Hinsehen, genau diese "Erweichung" - die daher alles andere als eine Erweichung ist - die besondere Pointe von Rilkes Sonett. Die syntaktische und auch thematische Gliederung von Rilkes Gedicht läuft nämlich nicht indifferent neben der metrischen her, sondern ist sehr wohl an dieser orientiert. Denn bis zu einem wohl definierten und kalkulierten Punkt im Sonett hinkt die Syntax gewissermaßen der metrischen Gliederung nach, bildet also eine Art Versatz heraus: Der erste größere syntaktische und thematische Einschnitt des Gedichts, als Satzanfang mit »Denn" (V. 5) markiert, ist in Bezug auf den Beginn des zweiten Quartetts um vier Silben sverspätet; auch die mit dem ersten Terzett korrespondierende Satz- und Sinneinheit, von der Konjunktion "bis" (V. 9) eingeleitet, läuft der metrischen Strukturierung noch um drei Silben nach. Ab dem zehnten Vers fallen dann die syntaktischen Einschnitte plötzlich auffallend harmonisch mit der metrischen Gliederung zusammen. Die Versumbrüche korrespondieren mit der Satzstruktur, der Übergang vom ersten zum zweiten Terzett ist als neue syntaktische und auch thematische Einheit realisiert, die wiederum ihre Binnengliederung glatt und elegant mit den Versumbrüchen vollzieht. Rilke spielt also offensichtlich mit dem »Verhältnis von Spannung und Lösung«; er nutzt die vom Sonett formal vorgegebene Lautstruktur, um darin performativ einzutragen, wovon sein Sonett auf der thematischen Ebene erzählt. Die metrische Gliederung schreibt der Aussage, die »einer« über seine Freundin tätigt den Abstand ein, die, wie oben dargestellt, die-

55 Pfeiffer, Über zwei Gedichte von Rilke (wie Anm. 11), S. 157.

Rainer Maria Rilkes »Die Flamingos« 185 
se 'Zuschreibungskonstellation` (sprechendes männliches Subjekt versus passives weibliches Objekt) mit sich bringt. Das der Freundin beigemessene Prädikat "sanft von Schlaf» (V. 5) ist im Vollzug des Sonetts vom 'Sein der Freundin in sich selbst< (»sie war", V. 4) durch den starken metrischen Bruch abgetrennt. Dieser Bruch stellt den Abstand der repräsentationalen Subjekt-Objekt-Relation aus - und streicht diese damit zugleich performativ durch.

Der Überschuss, der nun syntaktisch den Beginn der Einheit des ersten Terzetts aufschiebt, ist anderer Art. Wie bereits dargelegt, vollzieht sich hier, aufwändig inszeniert, die charakteristische Wendung, die den zuvor dargestellten und kritisierten und bis dorthin scheinbar mitvollzogenen "Repräsentationscharakter[] von Kunst« zu einem anderen Verhältnis wandelt, nämlich hin auf das Selbstverhältnis einer "Dingwerdung « ${ }^{56}$ Handwerklich gekonnt setzt Rilke diese Wendung genau auf die Schnittstelle zwischen Oktett und Sextett, die traditionell im Sonett eine solche Volta genannte Wendefigur vorsieht. Was also auf den ersten Blick wie eine »wesenswidrige[] Erweichung einer vorgegebenen Struktur « anmutet, affirmiert diese tatsächlich auf raffinierte Art und Weise. In ihr hallt gerade durch das unerwartete Enjambement, das die Volta noch auflädt, die Tradition des Sonetts wider. Mehr als das: Hatten das die beiden Quartette überspielende Enjambement und der Abstand zwischen syntaktischer und metrischer Gliederung die dort thematische Kunst-Konstellation durchgestrichen und verneint, so vollzieht der überraschende Übergang von Oktett ins Sextett die gegenteilige Geste. Was hier, als >Abstand zwischen syntaktischer und metrischer Gliederung scheinbar 'vereinzelt das Oktett überschießt und am Beginn des Sextetts zu stehen kommt, ist der Kern, ist das Wesen des Dinges und seines Werdens: »sich selber«. Es ist nicht problematischer Abstand zwischen Sein und Zuschreibung (Repräsentation) -, sondern produktiver Abstand, der das generative Selbstverhältnis erst ermöglicht, durch den sich das Ding als Ding konstituiert. Dieses "sich selber " taucht unvorhergesehen und 'zu viek im `Niemandsland zwischen Oktett und Sextett auf, es repräsentiert nichts - und ist genau dadurch eine zentrale metapoetische Figur. In ihm materialisiert sich die Volta, ein spannungsvolles Selbstverhältnis, aus dem sich das Gedicht-Ganze herausspreizt. Es ist dieser Versatz, der

56 Neumann, Rilkes Dinggedicht (wie Anm. 26), S. 151.

186 Johannes Ungelenk 
hier plötzlich auf sich aufmerksam macht, der das Sonett zum Klingen bringt: der Abstand, der Klang und Widerhall trennt und zugleich auf einander bezieht, und dabei eine generative, bedeutungserzeugende Differenz hervorbringt. Dieser in das Gedicht eingetragene Abstand sorgt dafür, dass es sich als Sonett auf die Form des Sonetts beziehen kann, ohne schlicht sich selbsterfüllend schal und ssterik leerzulaufen. Das Ergebnis gleicht dem Verhältnis der Phrynen bei Baudelaire: Im Selben, auf Lesbos, zieht das eine, nicht wesenhaft vom anderen Geschiedene, doch das andere an, so dass nie ein Seufzer ohne Echo bleibt.

Wie Rilkes »Die Flamingos" mustergültig vorführen, konstituiert sich das Sonett auf verschiedensten Ebenen als dieses Spiel zwischen Seufzer und leicht versetztem und deshalb generativem Echo:

\section{1. als thematischer Selbstbezug von durch die Volta verbundener These und Antithese;}

2. als intertextuelles Echo auf die literaturhistorische Tradition, was sowohl formale als auch motivische und thematische Anschlüsse einbegreift;

3. vor allem aber, ganz unmetaphorisch, tatsächlich als sich aus Klang und Echo, auf sich selbst horchend, aus sich selbst Hervorbringendes. $^{57}$

57 Paul de Man beobachtet in seinen berühmten Rilkelektüren etwas sehr ähnliches. Die "Vollendung", die Rilke als "Handwerker des Wohllauts" schafft, ist «in erster Linie lautlicher Art«; an einer Reihe von Gedichten zeigt de Man, dass - genau wie oben an den »Flamingos" herausgearbeitet - Rilke die konventionelle »Rhetorik des Gedichts als Instruments des Subjekts, des Objekts oder der Beziehung zwischen beiden« hinter sich lässt und durch einen Selbstbezug des Gedichts auf seine Materialität ersetzt: "Der Referent des Gedichts ist ein Attribut ihrer Sprache, in sich selbst ohne semantische Tiefe; die Bedeutung der Gedichte liegt in der Eroberung technischen Geschicks, das sie durch ihren akustischen Erfolg anschaulich machen." Allerdings wendet de Man dieses Phänomen, das er "Phonozentrismus" nennt, im Verlaufe seiner Lektüre immer stärker ins Problematische: "Da Klang das einzige Vermögen von Sprache ist, das ihr wirklich eigen ist und das keine Beziehung zu irgendetwas aufweist, das außerhalb der Sprache selbst gelegen wäre, wird er als das einzig verfügbare Mittel übrigbleiben.", schreibt er. Letztlich depotenziert de Man die "Rilkeschen Totalisierungen", die auf dem Bezug zur Klanglichkeit und Materialität der Signifikanten basieren, aufgrund ihres "Verlust[es] von Referentialität« zur mehr oder weniger leeren, jedenfalls enttäuschenden "List«, vgl. Paul de Man, Tropen (Rilke). In: Ders., Allegorien des Lesens. Frankfurt a.M. 1988, S. 52-90, hier S. 62-79. Diese Depotenzierung und Aufrechnung auf eine Erwartung von konventioneller Referenzialität scheint mir jedoch Rilkes dichterischem Projekt nicht gerecht zu werden. Aus meiner Sicht ist es genau die Aufgabe der Lektüre, die dem vom Handwerker Rilke hergestellten Produkt innewohnenden Widerständigkeit - auch das ist ein Bezug zur umgebenden Welt! - zu entwickeln und auf diese Weise sein komplexes Potenzial an Intervention zu entfalten. 
Rilkes Sonett unterwirft sich nicht schlicht dem Reimzwang seiner Form; es übererfüllt die metrischen Vorgaben auf eine Art und Weise, die dem Gedicht zweifellos ein klangliches "Mit-sich-Gesättigtsein« zu attestieren erlaubt. Mit Ausnahme nur des ersten und des letzten Reimpaars (auf die zurückzukommen ist!) erfüllen alle [!] Reimpaare ihren Gleichklang über, d.h., sie sind entweder über eine zusätzliche Assonanz des dem betonten, reimenden Vokal vorangehenden Vokals oder durch für den Reim nicht notwendige Identität des vorangehenden Konsonanten angereichert. Obwohl gar nicht auf den ersten Blick ersichtlich und dennoch am deutlichsten ist dies in den Versen sechs und sieben ausgeprägt: »leicht gedreht« und »einem Beet« klingen vokalisch schon ab der vorletzten betonten Silbe gleich, lagern dem stumpfen Reim also gleich zwei assonierende Silben vor.

Diese schon an den Versenden aufscheinende klangliche Dichte zieht sich durch das gesamte Sonett. Rilke verwebt vokalische und konsonantische Klangfäden, die er durch geschickte Anreicherung erst spinnt, zu einem dichten Klangtextil. Diese Metapher ist ein hilfloses, aber notwendiges Werkzeug der Beschreibung; denn Rilkes handwerklicher Umgang mit dem Klangmaterial steht keineswegs in einem rein instrumentellen Verhältnis im Dienste der Illustration oder Expression von intendierter Bedeutung. Was Rilke über Cézannes Umgang mit den Farben sagt, muss auch seinem eigenem Einsatz der Laute/Klänge zugebilligt werden; "Ihr Verkehr untereinander: das ist die ganze« - Dichtkunst, ist man geneigt zu ergänzen.

Wer dazwischenspricht, wer anordnet, wer seine menschliche Überlegung, seinen Witz, seine Anwaltschaft, seine geistige Gelenkigkeit irgend mit agieren läßt, der stört und trübt schon ihre Handlung. ${ }^{58}$

Und dennoch seien, nachvollziehend, exemplarisch einige dieser Fäden aufgedröselt, um der unhintergehbaren Materialität des Rilkeschen Sonetts ein wenig gerechter zu werden. So konstituiert sich ein typischer Klangfaden aus dem frikativen konsonantischen Anlaut [fr]: "Fragonard« (V. 1), »Freundin« (V. 4) und »Phryne« (V. 8) finden sich so lautlich verbunden, später gesellt sich auch, thematisch kontrastierend und diese Gruppe aufhebend, auch das »Fruchtrot» (V. 11) dazu. Verwoben ist die-

58 Rilke, Briefe über Cézanne (wie Anm. 8), S. 628.

188 Johannes Ungelenk 
ser Faden mit der lautmalerischen, vokalischen Färbung einzelner Versgruppen, die Rilke auch explizit mit visueller Farbigkeit verbindet. Der Umlaut [ö] der »Röte« (V. 2), den der Reim mit »böte» (V. 3) etabliert, färbt das erste Quartett und ist über das Frikativ [r] an den [fr]-Faden geknüpft. Sein Komplementärkontrast, das »Grüne« (V. 5), bestimmt die Farbgebung auf den Umlaut [ü] des zweiten Quartetts. Wieder ist es das Frikativ [r], das den Anschluss an den konsonantischen Faden herstellt. Beide, vokalische wie konsonantische Fäden, verdichten sich im zweiten Quartett stark: "blühend" greift in der Versmitte das [ü]-Thema auf, bevor der achte Vers es insistierend mit dem konsonantischen [fr]-Motiv engführt: "verführen sie verführender als Phryne«. Die griechische Hetäre ist so unschwer als aus Lautmaterial gestalteter Knoten zu erkennen. Das erste Terzett scheint lautlich unauffällig - doch versteckt sich hier nicht nur thematisch die Farbigkeit: Just in jenem elften Vers ereignet sich eine Art klangliche 'Epiphanier. Alle Vokale finden sich hier in einer serien- und harmonisch-wellenhaften angeordneten Abfolge [i e a u o (i e)] versammelt. Es ist ein Moment der Vollkommenheit, vom dem das Sonett spricht (von Schwarz wie Tod bis Fruchtrot wie Leben und Fortpflanzung) und den es performiert, während es über das bergende Selbstverhältnis des Dinges, "Der Flamingos« - das heißt metapoetisch auch von seinem eigenen, konstitutiven Selbstverhältnis als Kunstding Sonett -, reflektiert. Dieser versteckte, perfekte Wohlklang mag sich aber wohl nur gewissermaßen im Nachklang und kontrastiv Gehör verschaffen; er wird jäh unterbrochen vom lautmalerisch über die Assonanz auf [ei] ausgebauten Gekreische, das aus der Volière tönt (V. 12). Doch die oben bereits analysierte [ei]-Gruppe ist selbst ein Echo auf die Figur der Flamingos aus dem vorangegangenen Terzett (»Bleiche« (V. 9), »eigne Weiche« (V. 10)), so dass nicht verwundert, wenn die kurz erstaunten Flamingos den Misslaut in sich selbst aufnehmen und so aufheben: aus »kreischt ein Neid" (V. 12) wird "schreiten einzeln" (V. 14).

Es ist hier nicht die einzige Stelle, an der ein raufhebendes Echor einen aus dem Gefüge fallenden 'Extrempunkt` des Gedichts wieder lautlich in das Sonettganze integriert. Besonders deutlich und eindrucksvoll geschieht dies mit den beiden als contre-rejet und rejet, jeweils also als Überschuss in das zweite Quartett und das erste Terzett hineinragenden 'Resten`: Diese quasi vverwaisten Nachboten einer vorangegangenen 
syntaktischen Einheit manifestieren eine Spannung zur metrischen Gliederung, sie verkörpern eine Störung. Doch Rilke bindet sie, wahrscheinlich von den meisten Leserinnen unbemerkt, meisterhaft in die Klangkomposition ein. So ist "noch sanft von Schlaf» (V. 5) ein vokalisches Echo von "von Fragonard« ([o a o a $]$ ) - was, zusammen mit der oben bereits erwähnten Wiederaufnahme der [fr]-Gruppe in "Freundin", den Rokokokünstler lautlich mit der Aussage identifiziert. Der eigentümlich klingende Name lässt sich, nicht zufällig, aus dem Lautmaterial des vierten und fünften Verses rekonstruieren.

Ähnliches vollzieht sich mit dem die Volta verkörpernden `Kern ‘ des Sonetts, dem rejet "sich selber« aus Vers neun. Hier ist es eine Art an den Versbeginn verschobener 'Reim‘, der diese Phrase in den Klangraum des Gedichts integriert. Die ersten drei Silben des elften Verses, »in welcher«, sind nicht nur morphologisch analog gegliedert, sie lassen vokalisch exakt Vers neun widerhallen, zudem ist auch die konsonantische Struktur so ähnlich, dass die beiden Phrasen sich sogar unrein reimen. In schwächerem Maße, nämlich nur auf die Vokale bezogen, und hier auch mit leichten Abweichungen der Längen, klingen auch die Versbeginne zehn und dreizehn aneinander an ([i a e]). Da auch, wie oben festgestellt, die Verse zwölf und 14 lautlich über die [ei]-Gruppe verbunden sind, ist so eine das (End-)Reimschema supplementierende, ihm kontrapunktischentgegenlaufende zweite, alternierende Klanggliederung etabliert.

Solche echoartigen Klangzellen finden sich über das gesamte Gedicht verteilt (z.B. "Spiegelbilder wie« [V. 1]; »nicht mehr» und »wenn er« [V. 3f.]; [st]-Gruppe [V. 5f.]; [b]-Gruppe [V. 7] ...). Was Neumann auf der sdiegetischen Ebener der von ihm untersuchten Dinggedichtssonette, also im Hinblick auf das beschriebene 'Ding<, entdeckt, scheint auch, oder gar vor allem, für deren performative Ebene, also für den Sing-Akt des Sonetts, wahr zu sein: "Das Reden der Dinge ist zu denken als das Spiel der Reflexe, die in ihnen sind ${ }^{59}{ }^{9}$ Das Sonett materialisiert diese Klangreflexe, die "Dingwerdung", die sich in ihm, durch es und als es vollzieht; es konstituiert und artikuliert sich (auch im Sinne von gliedern) als klingender Selbstbezug.

Angesichts der starken lautlichen Überdeterminierung, die Rilkes Gedicht zweifelsohne auszeichnet, fällt ein Reimpaar auffällig aus der Rei-

59 Neumann, Rilkes Dinggedicht (wie Anm. 26), S. 154.

190 Johannes Ungelenk 
he: Ausgerechnet das letzte "Volière« - »Imaginäre« (V. 12 u. 14) findet mit seinem eigenartig technisch-fremdsprachlichen Register und dem betonten, sehr offenen Vokal [ä] keinerlei Anschluss im restlichen Sonett. Lässt sich das für den die äußere Störung hereintragenden zwölften Vers noch thematisch rechtfertigen, so ist das Enden des sonst so eng gewobenen Texts auf einen derart isolierten Laut doch erklärungsbedürftig. Semantisch schließt sich hier mit »ins Imaginäre« tatsächlich ein Kreis zu den "Spiegelbildern«, die das Sonett eröffnet hatten. Auffällig kontrastiert jedoch das 'monolithischer "Imaginäre" mit den ohnehin schon vervielfältigenden, und hier auch noch im unbestimmten Plural eingeführten "Spiegelbildern«. Schon am Beginn des Textes war ja eine Spannung zwischen Singular und Plural im Bezug der doppeldeutigen »ihrem « und »ihre« zu Tage getreten. Der abschließende Vers greift diese Spannung nun wieder auf und macht sie thematisch: "und schreiten einzeln ins Imaginäre«. Was zunächst unproblematisch und banal scheint, entpuppt sich bei näherem Hinsehen als kompliziert. Denn die Formulierung im Plural widerspricht dem Gesagten: Das Gedicht lässt ja genau nicht jeden Flamingo »einzeln" »schreiten", sondern fasst sie, wie im gesamten Gedicht geschehen, im Plural. Dennoch resümiert diese paradoxe Formulierung des 'Einzeln-Schreitens im spluralen Singular treffend das im Gedicht Erzählte: Auch die Figur des »sich selber«-Verführens war im Plural auf sdie Flamingos` bezogen gewesen und zielte dennoch auf die Formation einer reichen, in sich geschlossenen Einheit. Diese ist offenbar nicht schon in den 'Dingen mitgegeben, mit denen sich der Künstler konfrontiert sieht, die er sich vornimmt, seien es die Modelltiere im Jardin des Plantes oder andere `Gegenstände` der Dingdichtung. Das »Imaginäre«, in dem ein Ding schließlich als Ding »einzeln« steht, bezeichnet den Endpunkt eines künstlerischen Prozesses, der gewissermaßen eine erhöhte Realität produziert. Wieder mag die nuancierte Lautstruktur diesen Gedanken leiten: Das letzte, isolierte Reimpaar "Volière» - "Imaginäre" interagiert mit dem ersten, »Fragonard « - »sie war«. Der Gleichklang des vorletzten, unbetonten Vokals »i« und des auslautenden Konsonanten "r« hat einen interessanten Effekt: Durch das zusätzliche unbetonte »e« erscheint das "ä« wie eine durch eine grammatische Operation erzeugte Derivation - etwa eine Steigerung (sowie aus gro/s - grö/ser wird). »Imaginäre« interagiert mit »sie war«; als eine Art Resonanz oder Oberton- 
phänomen klingt das virtuelle Echo "sie wäre" mit. Das »Imaginäre« etabliert sich so als eine gesteigerte Realität, die sich vom bloßen Sein des "sie war" unterscheidet. Das Sonett erzählt den Prozess, den Weg der Wandlung von Material in ein 'Ding`, was Gerhard Neumann treffend »Überschreitung des Repräsentationscharakters von Kunst hin auf eine >Dingwerdung ${ }^{60}{ }^{60}$ genannt hatte. Die Flamingos »steigen« (V. 5), sie »verführen [...] / sich selber" (V. 8f.), und »schreiten« schließlich »einzeln ins Imaginäre (V. 14). Ganz in diesem Sinne identifiziert Hans Berendt »das Imaginäre« mit dem Raum des Orphischen: ${ }^{61}$ Aus den Flamingos, aus der Gruppe beobachtbarer Vögel wird "Die Flamingos" - das Sonett. Es ist Klang, es ist Echo, als überschreitender und aufhebender Übergang, der von der Gefangenschaft, der Begrenzung der »Volière" ins »Imaginäre führt und auch dort, in dieser mitsichselbstgesättigten Fülle, jene noch zu bergen weiß.

Das Rilkesche Dinggedicht ist nicht Dinggedicht, weil es ein `Ding repräsentierte. Dinggedicht ist, wo Kunstding und das `Ding«, dem das Gedicht 'gewidmet scheint, zusammenfallen. Wo ein Ding im dichterischen Vollzug entsteht, aus tönendbedeutendem Material; wo diese Klänge "sich selber« affizieren, weil das entstehende Ding stetig angestrengt in die eigene Tiefe horcht und sich so eine mitsichgesättigte, in sich artikulierte Geschlossenheit konstituiert, die nicht nur beliebiger Gegenstand ist, sondern unerhörte Bewegung, ja nie ganz erschöpfliche Fülle in sich birgt. Rilkes »Die Flamingos« führt das, sich selbst auslegend, eindrucksvoll vor. Was eignet sich für ein solches Dinggedicht besser als Sonett zu sein - dieses Kling(-ge-)ding - »[o]ù jamais un soupir ne resta sans écho«? ${ }^{62}$

60 Ebd., S. 151.

61 Hans Berendt, Rainer Maria Rilkes neue Gedichte. Versuch einer Deutung. Bonn 1957, S. 324 .

62 Auch die berühmten Wendungen "Entwicklung zum sachlichen Sagen" (Rilke, Briefe über Cézanne [wie Anm. 8], S. 622) und "Ich lerne sehen« (Rilke, Die Aufzeichnungen des Malte Laurids Brigge [wie Anm. 7], S. 456) scheinen von diesem Echo heimgesucht.

192 Johannes Ungelenk 